\title{
Determination of the Fe-Cr-Mo Phase Diagram at Intermediate Temperatures using Dual-Anneal Diffusion Multiples
}

Siwei Cao and Ji-Cheng Zhao

(Submitted August 17, 2015; in revised form October 11, 2015; published online November 5, 2015)

\begin{abstract}
A recently developed dual-anneal diffusion-multiple approach is employed to the determination of the $\mathrm{Fe}$-Cr-Mo phase diagram at intermediate temperatures. Diffusion multiples of $\mathrm{Fe}-\mathrm{Cr}$-NiCo-Mo were first annealed at $1200{ }^{\circ} \mathrm{C}$ for $500 \mathrm{~h}$ to create wide ranges of solid solution compositions. Subsequent annealing of the diffusion multiples at individual intermediate temperatures induced various precipitate phases. Electron probe microanalysis (EPMA) across the interface between large precipitates and the matrix phase provided local equilibrium information for the establishment of equilibrium tie-lines which are utilized to construct the Fe-rich part of the $\mathrm{Fe}-\mathrm{Cr}-\mathrm{Mo}$ isothermal sections at 900 and $800{ }^{\circ} \mathrm{C}$. The Mo-rich part of the isothermal sections at intermediate temperatures was not obtained due to the sluggish kinetics of precipitation and growth, resulting in too small precipitates for reliable EPMA composition evaluation. A complete $1200{ }^{\circ} \mathrm{C}$ isothermal section of the $\mathrm{Fe}-\mathrm{Cr}$-Mo system is also established from EPMA data on a water quenched diffusion multiple that was annealed at $1200{ }^{\circ} \mathrm{C}$ for $500 \mathrm{~h}$ only without a second anneal.
\end{abstract}

Keywords diffusion couples, experimental techniques, intermetallic compound, iron alloys, local equilibrium, phase transformation, ternary phase diagram

\section{Introduction}

The Fe-Cr-Mo ternary phase diagram is very significant to steel research and design since both $\mathrm{Cr}$ and Mo are key alloying elements of many steel compositions, especially stainless steels. Most steels are used at or below the intermediate temperatures (about $600-900{ }^{\circ} \mathrm{C}$ for $\mathrm{Fe}-\mathrm{Cr}$ $\mathrm{Mo}$ ), thus phase diagrams at these temperature ranges are very significant to assess the stability of steels at long-term service conditions. In addition, intermediate temperature phase diagrams are also very important for reliable assessment of thermodynamic parameters that are used to predict

This article is an invited paper selected from presentations at the Hume-Rothery Award Symposium on "Multicomponent Alloy Metallurgy, the Bridge from Materials Science to Materials Engineering," during TMS 2015, held March 15-19, 2015, in Orlando, Fla., and has been expanded from the original presentation. This symposium was held in honor of the 2015 Hume-Rothery award recipient, William Boettinger, for outstanding contributions to thermodynamics and kinetics of metallurgical systems and their application to the understanding of alloy microstructures and the relationship to processing conditions.

Siwei Cao and Ji-Cheng Zhao, Department of Materials Science and Engineering, The Ohio State University, 2041 College Road, Columbus, OH 43210, USA. Contact e-mail: zhao.199@osu.edu.

the driving force for phase transformation at the intermediate temperature ranges. ${ }^{[1]}$

The early experimental information on the phase diagram of the Fe-Cr-Mo ternary system was assessed by Raynor and Rivlin in 1984 and $1988^{[2,3]}$ Raghavan updated the phase diagram assessment with experimental results up to $1994 .{ }^{[4]}$ The most recent assessment of the Fe-Cr-Mo ternary system was performed by Kroupa in 2008. ${ }^{[5]}$ The Fe-Cr-Mo phase diagram contains two solid solutions (bcc $(\alpha)$ and fcc $(\gamma)$ ), four binary intermetallic compounds/phases (the $\sigma, \mu, \lambda$ (the Laves phase) and R phases), and one ternary phase (the $\chi$ (Chi) phase which was denoted as $\tau_{1}$ in the early literature and in Ref 5). All the binary intermetallic phases have significant solubility of the third element. Jin ${ }^{[6]}$ constructed two isothermal sections at 1100 and $1200{ }^{\circ} \mathrm{C}$ using electron probe microanalysis (EPMA) of diffusion triple specimens. Tie-lines of $\mathrm{bcc} / \sigma, \mathrm{bcc} / \mu, \mathrm{bcc} / \chi$ and $\chi / \mu$ phase equilibria were obtained. Jin reported that the bcc miscibility gap in the Cr-Mo system might extend above $1200{ }^{\circ} \mathrm{C}$ in the ternary. As a continuation of the study by Jin, ${ }^{[6]}$ Andersson and Lang ${ }^{[7]}$ performed a more comprehensive experimental study of the Fe-Cr-Mo system at 950, 1000, 1100, and $1200{ }^{\circ} \mathrm{C}$ using both EPMA and energy dispersive spectroscopy (EDS) analysis of diffusion triples. They also performed thermodynamic assessment of the Fe-Cr-Mo system based on their own data as well as those reported in the literature. Liu et al. published partial and complete experimental phase diagrams at $850,1050,1100,1180$, 1200 and $1250{ }^{\circ} \mathrm{C}^{[8-11]}$ These investigations ${ }^{[6-11]}$ together confirmed the approximate temperature ranges (Table 1) of existence for the $\mu, \sigma, \lambda, \mathrm{R}$, and $\chi$ phases and depicted a much clearer picture on the overall topology of the $\mathrm{Fe}-\mathrm{Cr}$ Mo ternary phase diagram. There are still significant discrepancies in the reported results, especially concerning 
the phase equilibria at intermediate temperatures. This study intends to collect more experimental data at the intermediate temperatures as input to future thermodynamic modeling/ reassessment to improve the reliability of phase stability prediction of the Fe-Cr-Mo system.

\section{Experimental Method and Procedure}

A diffusion multiple is an assembly of several metal blocks arranged in a pre-designed geometry to allow many diffusion couples and triples to be assembled in a single sample. It has been applied to effective determination of phase diagrams by taking advantage of the local equilibrium at the phase interfaces. ${ }^{[12-14]}$ A dual-anneal diffusion multiple (DADM) is a recent extension of the diffusionmultiple methodology in order to systematically study both phase transformations and intermediate-temperature phase diagrams. ${ }^{[1]}$ A DADM is first annealed at a high temperature to quickly form solid solutions and intermetallic compounds through relatively fast diffusion. A second/subsequent anneal of the diffusion multiple at an intermediate temperature would induce phase precipitation from the supersaturated solid solutions, thus allow determination of phase equilibria as well as studying phase transformations across wide compositions at the temperature of interest. In a certain sense, first diffusion anneal is equivalent to making many compositions and the second heat treatment is equivalent to performing annealing at a temperature of interest of many individually made alloys. The DADM method can avoid the time and cost of making many individual alloys and can render much more systematic investigations due to the continuous variations of composition in single phase regions formed during the high temperature annealing. It also circumvents the slow diffusion kinetics and shallow diffu- sion zones that would occur if a diffusion multiple is only annealed at an intermediate temperature (without the hightemperature anneal). In addition, DADMs offer an amazing diversity of precipitate microstructures and contain rich information on phase transformations. ${ }^{[1]}$

The DADMs used for this study were made up of pure elements of $\mathrm{Fe}, \mathrm{Cr}, \mathrm{Ni}, \mathrm{Co}$, and $\mathrm{Mo}$; and contained eight diffusion triples: $\mathrm{Co}-\mathrm{Cr}-\mathrm{Fe}$, Co-Cr-Mo, Co-Fe-Ni, Co-Mo$\mathrm{Ni}$, Cr-Fe-Mo, Cr-Fe-Ni, Cr-Mo-Ni, and Fe-Mo-Ni, as shown by the dashed circles in Fig. 1(b). The samples are exactly the same as those described in our work for the FeCr-Ni ternary system, ${ }^{[1]}$ where the experimental details can be found. The current article reports the results for the FeCr-Mo ternary system obtained from the Fe-Cr-Mo trijunction marked as a square in Fig. 1(a). The results of the other six ternary systems will gradually be published in the future when the analysis is complete.

Since the diffusion multiples are made via hot isostatic pressing (HIP) at $1200{ }^{\circ} \mathrm{C}$ and then annealed at $1200{ }^{\circ} \mathrm{C}$ for $500 \mathrm{~h}$, one can probably assume that the stresses at $1200{ }^{\circ} \mathrm{C}$ are all relaxed after the $500-\mathrm{h}$ anneal at this temperature. During quenching from $1200{ }^{\circ} \mathrm{C}$ to ambient temperature, the difference in the coefficients of thermal expansion (CTE) of the various pure elements ( $\mathrm{Fe}, \mathrm{Cr}, \mathrm{Ni}, \mathrm{Co}$, and $\mathrm{Mo}$ ) in the diffusion multiples will lead to compressive stresses in certain regions and tensile residual stresses in other regions, resulting in cracking of brittle intermetallic compounds as well as delamination. The residual stresses on the order of $\sim 100 \mathrm{MPa}$ were estimated on similar diffusion multiples at room temperature. Such levels of stresses should have little effect on phase equilibria and may have a slight effect on precipitation. Nevertheless, the local equilibrium at the large precipitate phase and matrix should not have been affected by the residual stresses. There should already be significant stress relaxation during the dualanneal (e.g. $900{ }^{\circ} \mathrm{C}$ for $500 \mathrm{~h}$ ) too.

Table 1 Crystal structure and stable temperature ranges of the five intermetallic compounds observed in the Fe-Cr-Mo ternary system

\begin{tabular}{|c|c|c|c|c|}
\hline Phase & $\begin{array}{c}\text { Crystal structure } \\
\text { (Pearson symbol, space } \\
\text { group, prototype) }\end{array}$ & $\begin{array}{c}\text { Lattice } \\
\text { parameters (a), A }\end{array}$ & $\begin{array}{l}\text { Prior knowledge on } \\
\text { stable temperature range }\end{array}$ & $\begin{array}{l}\text { Phase stability observations } \\
\text { from the current study }\end{array}$ \\
\hline$\sigma$ & $t \mathrm{P} 30, \mathrm{P}_{2} / \mathrm{mnm}, \mathrm{CrFe}$ & $\begin{array}{l}\mathrm{a}=8.797-9.218 \\
\mathrm{c}=4.558-4.813\end{array}$ & $\begin{array}{l}\text { Upper limit: } 1610^{\circ} \mathrm{C} \\
\text { Lower limit: } 472{ }^{\circ} \mathrm{C}\end{array}$ & Observed at $1200,900,800$ and $700{ }^{\circ} \mathrm{C}$ \\
\hline$R$ & $h \mathrm{R} 159, \mathrm{R} \overline{3}, \mathrm{Co}_{5} \mathrm{Cr}_{2} \mathrm{Mo}_{3}$ & $\begin{array}{l}\mathrm{a}=10.910 \\
\mathrm{c}=19.354\end{array}$ & $\begin{array}{l}\text { Upper limit: } \sim 1650^{\circ} \mathrm{C} \\
\text { Lower limit: } \sim 930^{\circ} \mathrm{C}\end{array}$ & $\begin{array}{l}\text { Observed at } 1200^{\circ} \mathrm{C} \text {; observed as metastable } \\
\text { precipitates at } 900 \text { and } 800{ }^{\circ} \mathrm{C}\end{array}$ \\
\hline$\lambda$ (Laves) & $h \mathrm{P} 12, \mathrm{P}_{3} / \mathrm{mmc}, \mathrm{MgZn}_{2}$ & $\begin{array}{l}a=4.744-4.745 \\
c=7.725-7.734\end{array}$ & $\begin{array}{l}\text { Upper limit: } 927{ }^{\circ} \mathrm{C} \\
\quad \text { Lower limit: }-273{ }^{\circ} \mathrm{C}\end{array}$ & Observed at $900{ }^{\circ} \mathrm{C}, 800{ }^{\circ} \mathrm{C}$ and $700{ }^{\circ} \mathrm{C}$ \\
\hline$\mu$ & $h \mathrm{R} 39, \mathrm{R} \overline{3} \mathrm{~m}, \mathrm{Fe}_{7} \mathrm{~W}_{6}$ & $\begin{array}{l}\mathrm{a}=4.7546 \\
\mathrm{c}=25.716\end{array}$ & $\begin{array}{l}\text { Upper limit: } 1370{ }^{\circ} \mathrm{C} \\
\quad \text { Lower limit: }-273{ }^{\circ} \mathrm{C}\end{array}$ & Observed at $1200,900,800$ and $700^{\circ} \mathrm{C}$ \\
\hline$\chi\left(\tau_{1}\right)$ & $c \mathrm{I} 58, \mathrm{I} \overline{4} 3 \mathrm{~m}, \alpha \mathrm{Mn}$ & $\mathrm{a}=8.854-8.959$ & $\begin{array}{l}\text { Upper limit: } \sim 1190 \pm 10^{\circ} \mathrm{C} \\
\text { Lower limit: } \sim 550^{\circ} \mathrm{C}\end{array}$ & $\begin{array}{l}\text { Not observed at } 1200^{\circ} \mathrm{C} \text {; observed at } 900 \text {, } \\
800 \text { and } 700^{\circ} \mathrm{C}\end{array}$ \\
\hline
\end{tabular}

This table is mostly based on information from Ref 5

(a) The lattice parameters are a function of composition and the listed values are only those reported in the literature and do not cover the entire composition regions of the phases 


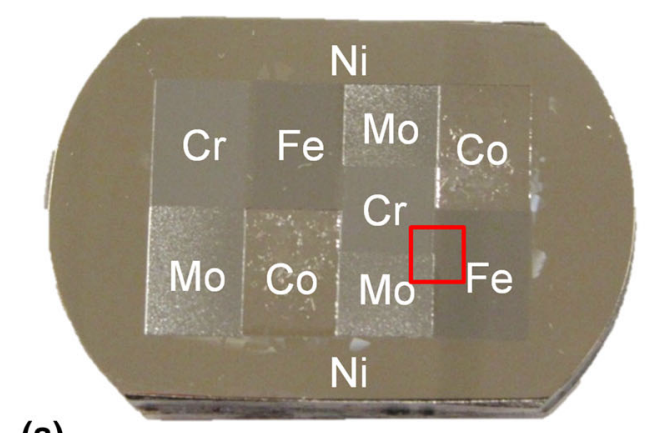

(a)

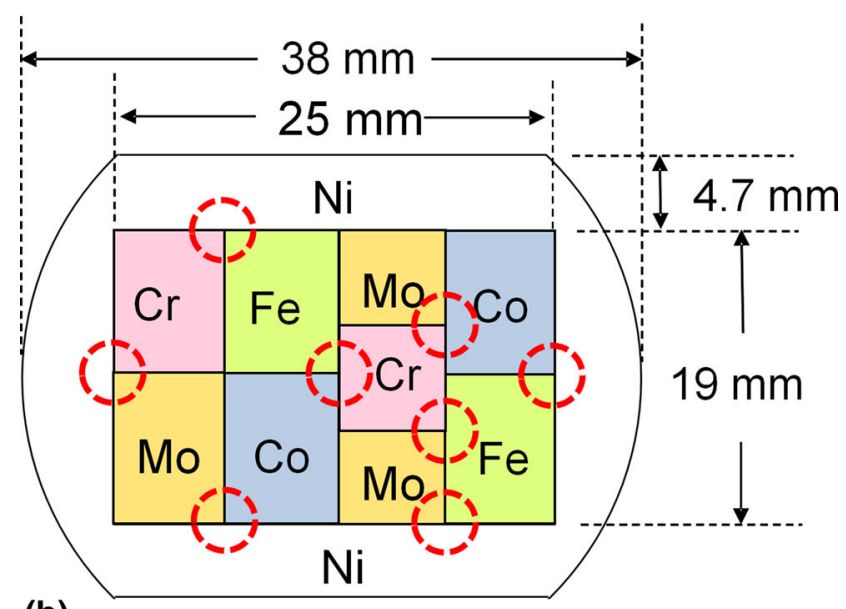

(b)

Fig. 1 Optical photograph (a) and schematic (b) of the Fe-Cr$\mathrm{Ni}$-Co-Mo diffusion multiple. The location of the Fe-Cr-Mo triple, where all the results were obtained, is marked as a square in (a)
The four diffusion multiple samples are listed for easy tracking: Sample \#1: $1200{ }^{\circ} \mathrm{C}-500 \mathrm{~h}$ single-anneal; Sample \#2: $1200{ }^{\circ} \mathrm{C}-500 \mathrm{~h}$ and $900{ }^{\circ} \mathrm{C}-500 \mathrm{~h}$ dual-anneal; Sample \#3: $1200{ }^{\circ} \mathrm{C}-500 \mathrm{~h}$ and $800{ }^{\circ} \mathrm{C}-1000 \mathrm{~h}$ dual-anneal; and Sample \#4: $1200{ }^{\circ} \mathrm{C}-500 \mathrm{~h}$ and $700{ }^{\circ} \mathrm{C}-1000 \mathrm{~h}$ dualanneal.

\section{Results and Discussion}

\subsection{Isothermal Section of Fe-Cr-Mo at $1200^{\circ} \mathrm{C}$}

SEM backscattered electron (BSE) images of the Fe-CrMo tri-junction in Sample \#1 $\left(1200{ }^{\circ} \mathrm{C}-500 \mathrm{~h}\right)$ are shown in Fig. 2. Literature results indicate that five phases are present in the $1200{ }^{\circ} \mathrm{C}$ isothermal section of Fe-Cr-Mo: the bcc phase $(\alpha)$, fcc phase $(\gamma)$, sigma phase $(\sigma)$, mu phase $(\mu)$, and $\mathrm{R}$ phase, respectively. The $\gamma$-Fe phase is of very high (>95 at.\%) Fe concentration and it is far from the center of SEM images, and thus not seen in Fig. 2. Since the $\alpha / \gamma$ equilibrium is already well established, no effort was made in the present study to re-determine it.

Careful examination of the Fe-Cr-Mo tri-junction using both optical and electron microscopy allowed preliminary identification of all the three intermetallic phases $(\sigma, \mu$ and R) that are sandwiched between the Mo-rich part of the $\alpha$ phase (light area at the bottom) and the $\mathrm{Cr}$ and $\mathrm{Fe}$ rich part of the $\alpha$ phase (dark area at the top), Fig. 2(b). Due to similar chemical compositions, the contrast between the intermetallic phases is very subtle in Fig. 2(b). Thin layers of the $\mu$ phase and the R phases can be seen in Fig. 2(c) along the $\mathrm{Fe} / \mathrm{Mo}$ interface. EPMA line scans were performed and most of them are marked in Fig. 2(b) with the scan numbers. Equilibrium tie-line information was
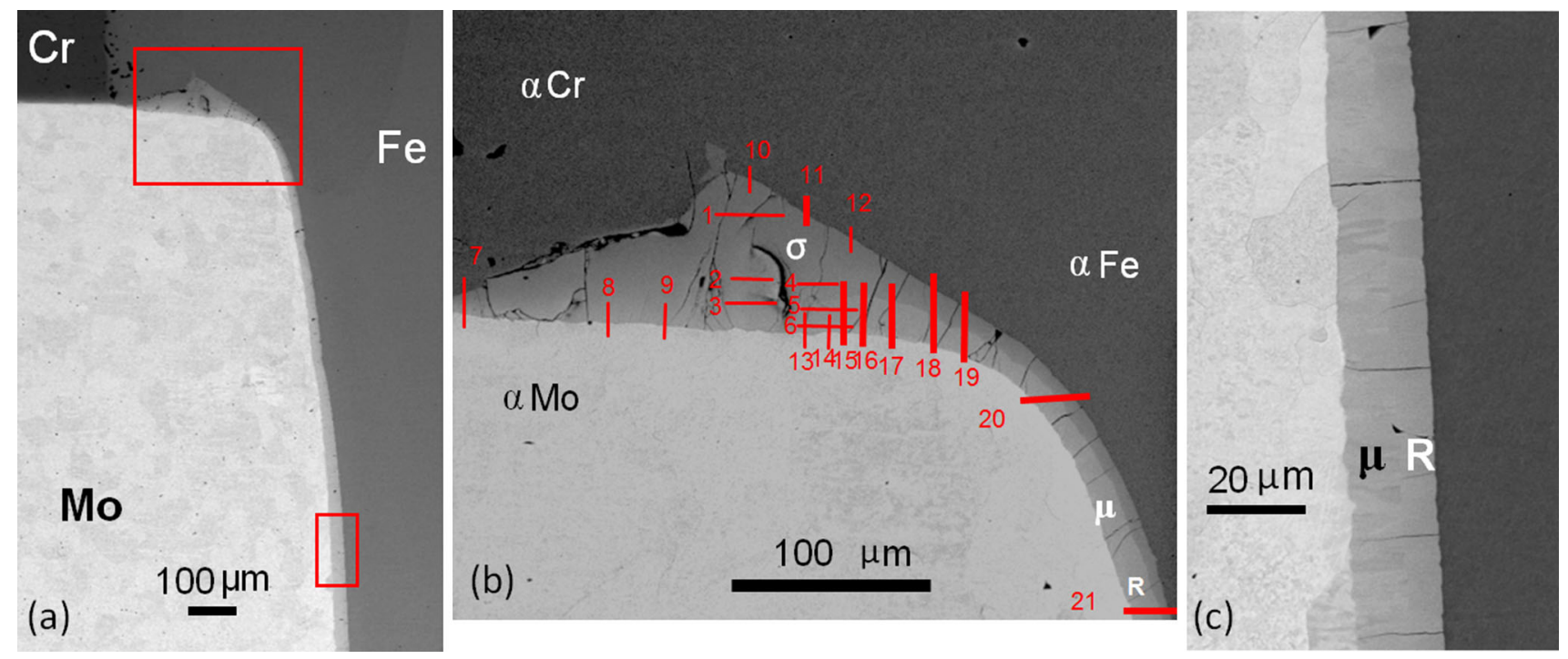

Fig. 2 SEM images of Fe-Cr-Mo tri-junction/ternary area in Sample $\# 1$ (1200 $\left.{ }^{\circ} \mathrm{C}-500 \mathrm{~h}\right)$ : (a) a low magnification image showing overall tri-junction region with the locations of the higher magnification images in (b) and (c) marked as rectangular boxes; (b) high magnification image showing the intermetallic phases and some of the EPMA line scan locations (the numbers are the EPMA scan numbers); and (c) high magnification image of the binary Fe-Mo area showing the intermetallic phases $\mu$ and $\mathrm{R}$ 


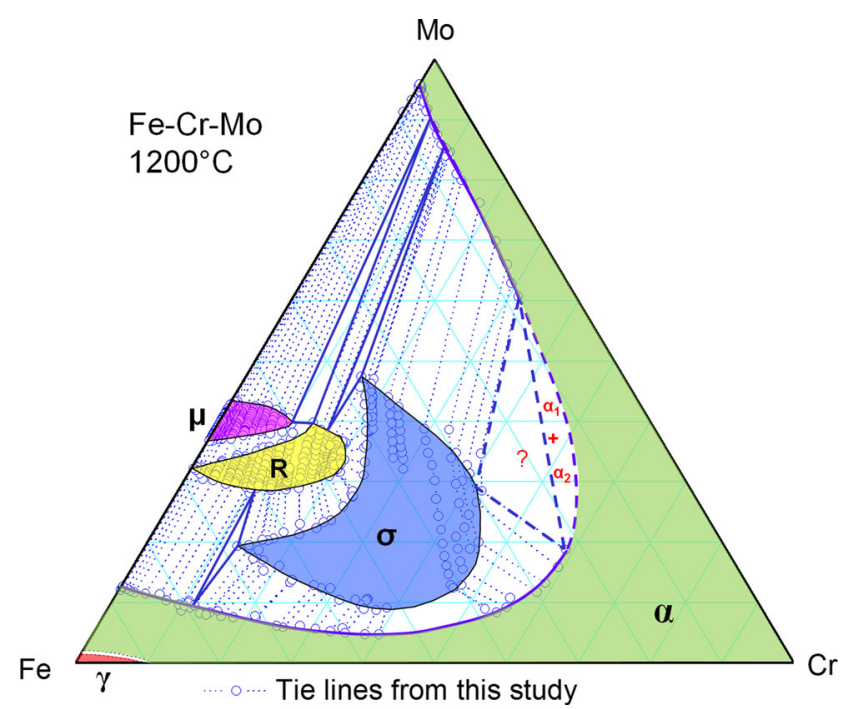

Fig. 3 The $1200{ }^{\circ} \mathrm{C}$ Fe-Cr-Mo isothermal section determined from EPMA on Sample \#1 $\left(1200{ }^{\circ} \mathrm{C}-500 \mathrm{~h}\right)$. The composition is plotted in at.\% axes with the axis numbers removed for simplicity

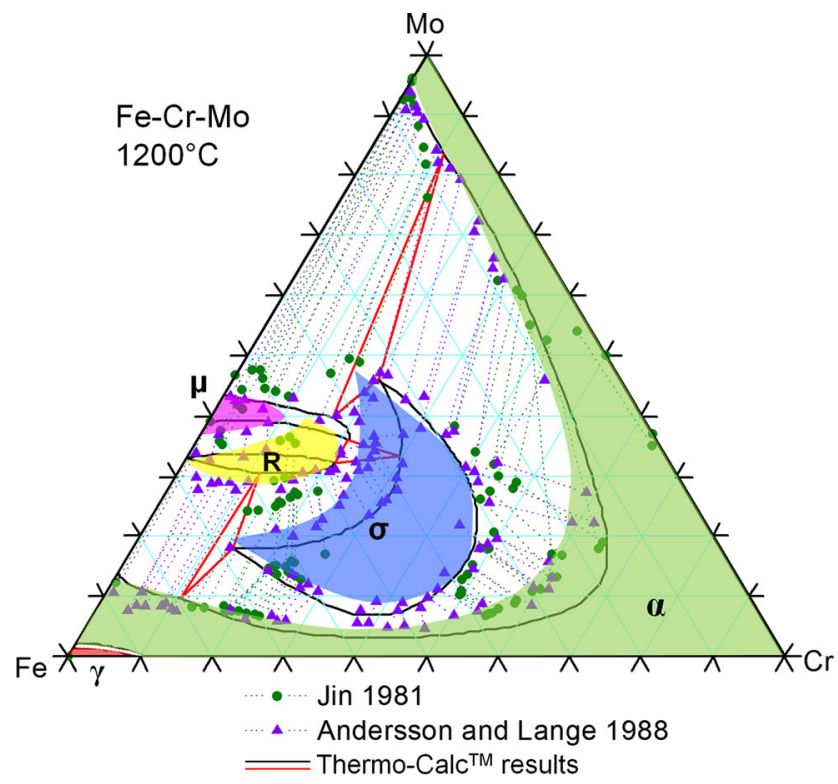

Fig. 4 Comparison of the current experimental results (shaded single-phase regions) on the isothermal section of Fe-Cr-Mo at $1200{ }^{\circ} \mathrm{C}$ with experimentally determined data reported in the literature (symbols and dotted tie-lines) as well as the computed results from Thermo-Calc ${ }^{\mathrm{TM}}$ (solid lines)

obtained by plotting the EPMA scan profiles in both composition-distance plots as well as plotting scan-line compositions onto the compositional triangle. Detailed procedure of such analysis can be found in Ref 15 .

The $1200{ }^{\circ} \mathrm{C}$ isothermal section of the Fe-Cr-Mo ternary system obtained from EPMA on Sample \#1 is shown in Fig. 3. It contains a large number of tie-lines and single- phase data points obtained by EPMA, showing phase equilibria between/among the $\alpha, \mu, \mathrm{R}$, and $\sigma$ phases. The $\gamma$ loop in Fe-rich corner of the isothermal sections was not experimentally measured (even though the information was available in the sample), and thus was only dashed in the phase diagram based on the information from the binaries. All the EPMA compositional data are presented as circles and the tie-lines are represented by dotted lines. The phase boundaries of single phase regions are extrapolated based on the consistency of tie-lines and available single-phase composition points for the intermetallics. Ternary phase regions are denoted as triangles. Part of the bcc $\alpha$ phase boundary is shown as a dashed line since the data trends seem to indicate the existence of a miscibility gap in Mo and $\mathrm{Cr}$ rich $\alpha$ phase, potentially creating an $\alpha-\sigma-\alpha$ three-phase equilibrium which is tentative and thus represented as a dashed triangle. The information from the current study represents a well-defined isothermal section for the $\mathrm{Fe}-\mathrm{Cr}$ Mo system.

At $1200{ }^{\circ} \mathrm{C}$, the $\mu$ and $\mathrm{R}$ phase regions in the ternary Fe$\mathrm{Cr}-\mathrm{Mo}$ isothermal section are extensions from their binary phases from Fe-Mo. The $\sigma$ phase that is stable above $1236{ }^{\circ} \mathrm{C}$ in the binary $\mathrm{Fe}-\mathrm{Mo}$ phase diagram and below $\sim 840{ }^{\circ} \mathrm{C}$ in $\mathrm{Fe}-\mathrm{Cr}$ is stabilized to $1200{ }^{\circ} \mathrm{C}$ with the addition of $\mathrm{Cr}$. It is clear that $\mathrm{Cr}$ stabilizes all the binary intermetallic phases of this ternary system. The single phase region of the $\sigma$ phase is shaped like a new moon with the tips pointing toward the binary Fe-Mo system. The Mo composition range of the $\mathrm{R}$ phase is very small for the binary Fe-Mo system, but it expands significantly in the ternary system with the addition of $\mathrm{Cr}$.

Figure 4 compares the current results with prior experimental data as well as the computed $1200{ }^{\circ} \mathrm{C}$ isothermal section using Thermo-Calc ${ }^{\mathrm{TM}}$ and the TCFE5 thermodynamic database. It is clear that the new results agree reasonably well with those reported by $\mathrm{Jin}^{[6]}$ and Andersson and Lang ${ }^{[7]}$ except that the $\sigma$ phase region is expanded to lower $\mathrm{Cr}$ concentrations in equilibrium with the $\mathrm{R}$ and $\mu$ phases. The results from this study and those of $\mathrm{Jin}^{[6]}$ and Andersson and Lange ${ }^{[7]}$ together clearly show that the existing thermodynamic assessment significantly underestimates the solubility of $\mathrm{Fe}$ and $\mathrm{Mo}$ in $\alpha$ (bcc) $\mathrm{Cr}$ and that the Cr-lean arm of the $\sigma$ phase region is significantly off. In addition, the computed shapes of the single-phase regions of both the $\mu$ phase and the $\mathrm{R}$ phase from Thermo-Calc ${ }^{\mathrm{TM}}$ are quite different from those reported from the current experimental measurements, indicating a need for a reassessment of the relevant thermodynamic parameters of these phases.

\subsection{Isothermal Section of $\mathrm{Fe}-\mathrm{Cr}-\mathrm{Mo}$ at $900^{\circ} \mathrm{C}$}

Figure 5 is an SEM BSE image montage of Sample \#2 $\left(1200^{\circ} \mathrm{C}\right.$ for $500 \mathrm{~h}$ and $900{ }^{\circ} \mathrm{C}$ for $500 \mathrm{~h}$ ), showing that precipitates of various morphologies and phases were formed during annealing at $900{ }^{\circ} \mathrm{C}$. Note that the $1200{ }^{\circ} \mathrm{C}$ for $500 \mathrm{~h}$ single-anneal diffusion multiple (Sample \#1, Fig. 2) showed no precipitates, indicating that the water quench after the $1200{ }^{\circ} \mathrm{C}$ annealing was able to retain all the single phase compositions to ambient temperature. All the 


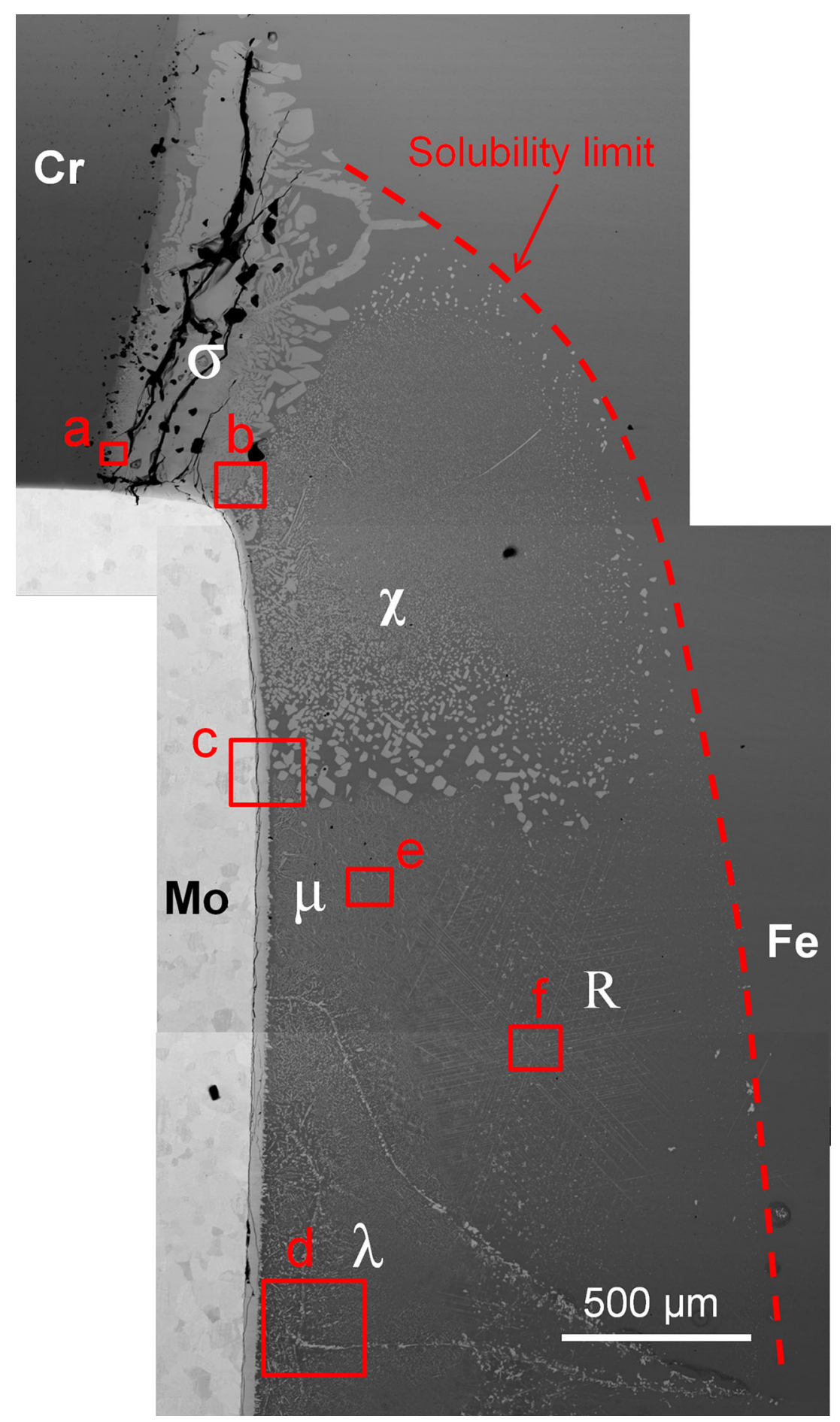

Fig. 5 SEM BSE image montage showing the phase precipitation in the Fe-Cr-Mo tri-junction area of Sample \#2 $\left(1200{ }^{\circ} \mathrm{C}-500 \mathrm{~h}+900{ }^{\circ} \mathrm{C}-500 \mathrm{~h}\right)$. High magnification images of various regions marked from a to $\mathrm{f}$ are shown in Fig. 6

area to the top and right of Mo beyond the thin hockey-stick shaped intermetallic phases was originally single-phase $\alpha$ before the $900{ }^{\circ} \mathrm{C}$ annealing. The $900{ }^{\circ} \mathrm{C}$ solubility limit of $\alpha$, which separates the precipitation regions from the precipitate-free region, is visible in Fig. 5 as the dashed line. Single-point EPMA measurements along this line provided the solubility information.

The blocky precipitates in the top region (Cr-rich) of Fig. 5 are the $\sigma$ phase. Higher magnification images of areas marked as "a" and "b" in Fig. 5 are shown in Fig. 6(a) and 

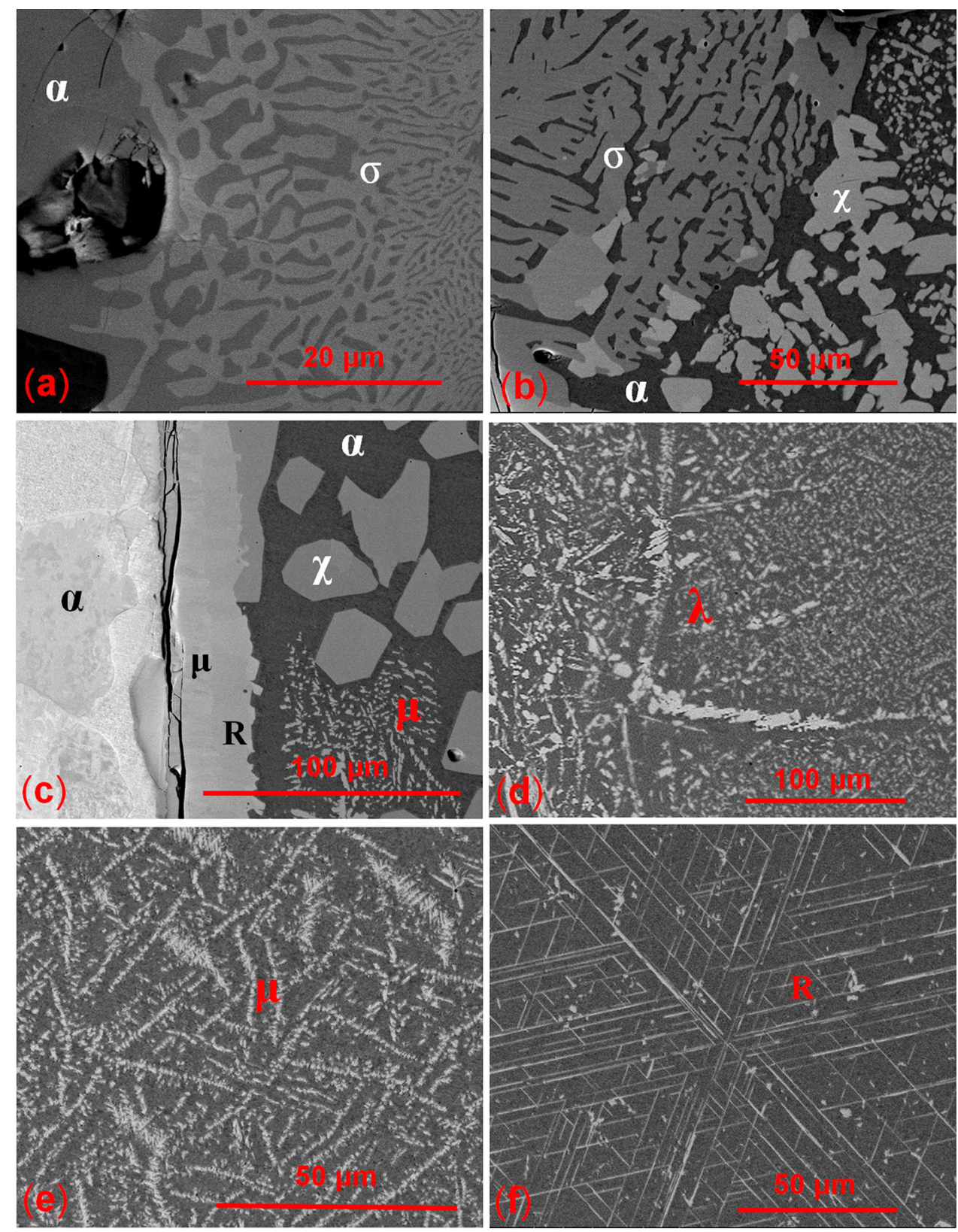

Fig. 6 SEM BSE images showing various precipitates in the Fe-Cr-Mo tri-junction of Sample \#2. The locations of these images are marked in Fig. 5

(b). Figure 6(a) shows the blocky $\sigma$ phase in the $\alpha$ matrix. Figure 6(b) shows the dark gray $\sigma$ phase, the light gray $\chi$ phase in the dark $\alpha$ matrix; capturing the $\alpha-\sigma-\chi$ three-phase equilibrium. The $\chi$ phase precipitates occupied a large neartop area in Fig. 5 and exhibited a predominately equiaxed morphology with widely varied precipitate sizes that will be the subject of a separate discussion in an upcoming article. Figure 6(c) is a high magnification image of area "c" in Fig. 5, showing the bright Mo-rich $\alpha$ phase on the left and the dark Fe-rich $\alpha$ phase matrix on the right. The large equiaxed precipitates are the $\chi$ phase and the small precipitates are the $\mu$ phase. It is emphasized that the thin layers of both $\mu$ and $\mathrm{R}$ formed at the $1200{ }^{\circ} \mathrm{C}$-annealing (in comparison with Fig. 2(c)) are still present after being annealed at $900{ }^{\circ} \mathrm{C}$ for $500 \mathrm{~h}$, Fig. $6(\mathrm{c})$. The $\mu$ is stable at $900{ }^{\circ} \mathrm{C}$ based on the $\mathrm{Fe}$-Mo binary phase diagram and the existing information of the Fe-Cr-Mo ternary phase diagram, thus it should stay; but the $\mathrm{R}$ phase is unstable at $900{ }^{\circ} \mathrm{C}$ and thus it should decompose to reach equilibrium. The difficulty in decomposing a high-temperature formed intermetallic compound at lower temperatures is the culprit that led to the residual $\mathrm{R}$ phase in Sample \#2. This important point has been discussed in detail separately ${ }^{[16]}$ and has important implications in interpreting equilibrium even for 
individually made alloys that usually go through a hightemperature homogenization annealing and a low-temperature equilibration annealing.

The bottom of Fig. 5, far away from the $\mathrm{Cr}$ piece (on the top-left corner), is essentially the Fe-Mo diffusion couple region without much Cr presence. The area " $d$ ", with its high magnification image showing in Fig. 6(d), has an average composition of $\sim 87.5$ at.\% Fe- 12.5 at.\% Mo. According to the binary Fe-Mo phase diagram, this composition should decompose to $\alpha$ and $\lambda$ two phases. The $\lambda$ (Laves) phase is a low temperature (stable up to $927^{\circ} \mathrm{C}$ ) intermetallic phase in the Fe-Mo binary system. As a matter of fact, all the compositions between area " $\mathrm{d}$ " to the solubility dashed line on the right at the bottom of Fig. 5 should decompose into $\alpha$ and $\lambda$ two phases to reach equilibrium.

A high magnification image of the $\mu$ phase precipitates in area "e" of Fig. 5 is shown in Fig. 6(e). The dendritic nature of the precipitates is very apparent. It seems very likely that the $\mu$ phase appeared first in this region of the $\alpha$ phase matrix as a metastable precipitate phase, which is been consumed by the formation of the $\chi$ phase above $(\mathrm{Cr}-$ richer region) and the $\lambda$ phase below (Cr-leaner region). If the diffusion multiple were annealed longer at $900{ }^{\circ} \mathrm{C}$, the entire region of the $\mu$ phase precipitates were likely be consumed by the formation of equilibrium phases $\chi$ and $\lambda$.

The needle/thin-plate-like R-phase precipitates in area "f" of Fig. 5 are shown in Fig. 6(f), exhibiting a beautiful Widmanstätten pattern. The R-phase precipitates also appear as a metastable phase during the decomposition of the $\alpha$ phase at $900{ }^{\circ} \mathrm{C}$ and it appears that the R-phase needles are being consumed by the formation of other equilibrium phases, $\chi$ and $\lambda$.

EPMA across the interfaces between the precipitates and the adjacent matrix phases and single point EPMA analysis along the solubility boundaries such as the red dashed line in Fig. 5 afforded the data shown in Fig. 7, which is a partial $900{ }^{\circ} \mathrm{C}$ isothermal section of the Fe-Cr-Mo ternary system. Only large precipitates were used in the EPMA scans for tie-line evaluation. This is to avoid the compositional supersaturation associated with the Gibbs-Thomson effect on small particles and to allow reliable evaluation of the composition of the precipitate phase (the particle size needs to be greater than the interaction volume of the x-ray production under the SEM electron beam). Details of such EPMA evaluation of intermediate phase diagrams are explained before. ${ }^{[1]}$

The results of EPMA single-point measurements of the Mo solubility in the Fe-rich $\alpha$ phase in the Fe-Cr-Mo system (e.g. along the dashed line in Fig. 5) agree well with the solubility line determined from tie-line analysis from EPMA scans across the precipitate/matrix interfaces, as shown in Fig. 7. The Mo-rich area of the isothermal section was left blank because the precipitates in this area of the compositions are too fine to allow reliable EPMA composition evaluation of the precipitates. Careful transmission electron microscopy (TEM) analysis or atom probe analysis will be necessary to obtain reliable compositional data to construct this part of the phase diagram. For the time being, the solubility of Mo in the Fe-rich $\alpha$ phase at $900{ }^{\circ} \mathrm{C}$ is well defined by the current experimental measurements. The single-phase composition region of the $\chi$ phase is also well defined. The phase equilibria around the $\chi$ phase should be very reliable since this phase precipitated out from the supersaturated solid solution without prior existence at $1200{ }^{\circ} \mathrm{C}$ and the precipitates are big enough to perform reliable EPMA analysis. The $\sigma$ phase region with less than $\sim 10$ at. $\%$ Mo is defined/determined, but that at $>10$ at. $\%$ Mo is not, as shown by the dashed line surrounding the $\sigma$ phase region. Our results clearly show that there is appreciable $\mathrm{Cr}$ solubility in the $\lambda$ phase, not zero as previously assumed during experimental phase diagram assessments $^{[2-4]}$ as well as during thermodynamic modeling. ${ }^{[7,17]}$ The finite Cr solubility leads to a $\alpha-\lambda-\chi$ three-phase equilibrium, which is consistent with the observation of Liu et al. at $850^{\circ} \mathrm{C}^{[8]}$

Figure 8 compares the current experimental data with results from thermodynamic calculations using Thermo$\mathrm{Calc}^{\mathrm{TM}}$ and the TCFE5 database. The thermodynamic calculation does a good job in predicting the solubility of Mo in Fe-rich bcc $(\alpha)$ phase. The experimentally measured $\chi$ phase region is larger than the thermodynamic prediction, but the thermodynamic calculation is doing a reasonably good job in predicting the $\alpha / \chi$ phase equilibrium. The thermodynamic calculations underestimated the stability of the $\lambda$ (Laves) phase; and the thermodynamic parameters need to be adjusted to include the $\mathrm{Cr}$ solubility in the $\lambda$ phase such that the $\alpha-\lambda-\chi$ three-phase equilibrium comes to existence in thermodynamic calculations of $\mathrm{Fe}-\mathrm{Cr}-\mathrm{Mo}$ at $900{ }^{\circ} \mathrm{C}$ and lower temperatures.

There are no experimental data available for Fe-Cr-Mo at exactly $900{ }^{\circ} \mathrm{C}$ for comparison. The closest available data from the literature are at $950{ }^{\circ} \mathrm{C}$ which were reported by Andersson and Lange. ${ }^{[7]}$ Considering the temperature difference, the results are reasonably consistent with the current data, Fig. 9.

\subsection{Isothermal Section of Fe-Cr-Mo at $800^{\circ} \mathrm{C}$}

Sample \#3 was first annealed at $1200{ }^{\circ} \mathrm{C}$ for $500 \mathrm{~h}$ and then at $800{ }^{\circ} \mathrm{C}$ for $1000 \mathrm{~h}$. A montage of SEM BSE images of the Fe-Cr-Mo ternary area (Fig. 10) shows the morphology and relative locations of the various precipitates. The overall distribution of the different precipitate regions is very similar to that of Sample \#2 (Fig. 5), but the precipitates are mostly at finer scales. The bottom location in Fig. 10 is far away from the $\mathrm{Cr}$ piece (on the top-left corner) and is essentially the Fe-Mo diffusion couple region without much $\mathrm{Cr}$ presence. The area "a", with its high magnification image showing in Fig. 11(a), has an average composition of $\sim 87.5$ at.\% Fe-12.5 at.\% Mo. According to the binary Fe-Mo phase diagram, this composition should decompose to $\alpha$ and $\lambda$ two phases. Figure 11(a) shows the bright blocky $\lambda$ phase and finer $\mu$ phase in the dark $\alpha$ matrix. The $\lambda$ phase grew at the expense of the metastable $\mu$ phase which precipitated out first. The equilibrium phases are $\lambda$ and $\alpha$, consistent with the binary Fe-Mo phase diagram.

Figure 11(b), taken from area "b" in Fig. 10, shows needle/thin-plate-like R-phase precipitates. The $\mathrm{R}$ phase is unstable at $800{ }^{\circ} \mathrm{C}$ and it precipitated as a metastable phase before the equilibrium phases. This area " $b$ " in Fig. 10 is 
gradually being consumed by the equilibrium $\chi$ phase from the top and the equilibrium $\lambda$ phase from the bottom. It is anticipated that at longer annealing time at $800{ }^{\circ} \mathrm{C}$, the $\mathrm{R}$ phase would be completely replaced by the equilibrium phases. The wide compositions created by the high-temperature $\left(1200{ }^{\circ} \mathrm{C}\right.$ in this case) annealing of a DADM allow

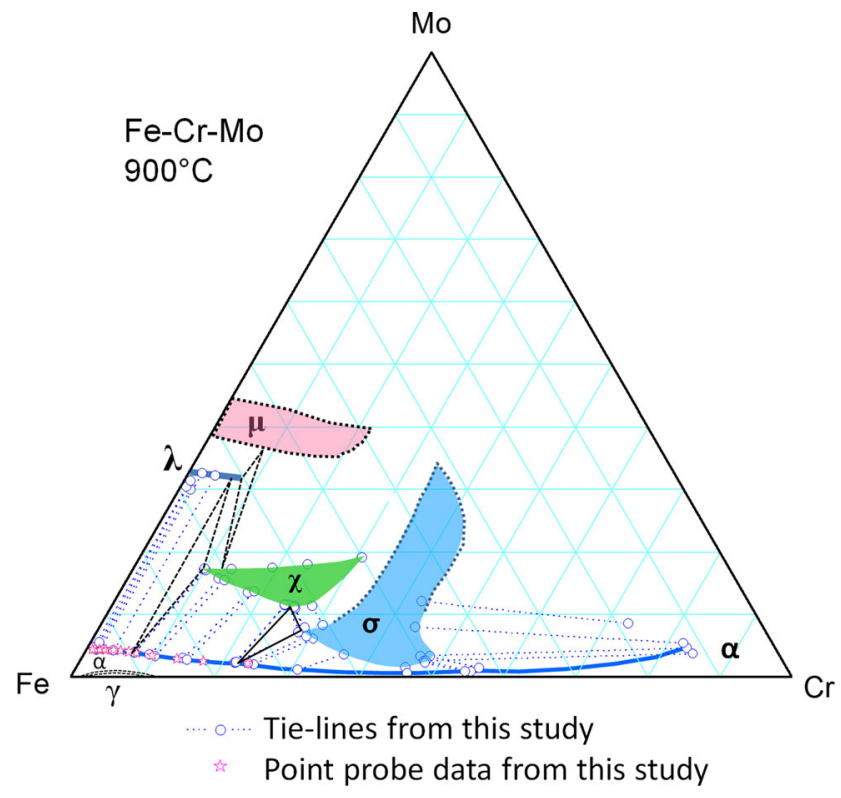

Fig. 7 Partial $900{ }^{\circ} \mathrm{C} \mathrm{Fe}-\mathrm{Cr}-\mathrm{Mo}$ isothermal section determined from this study. The composition is plotted in at.\% axes with the axis numbers removed for simplicity. The dashed phase boundaries are not experimentally determined but just to guide the eyes

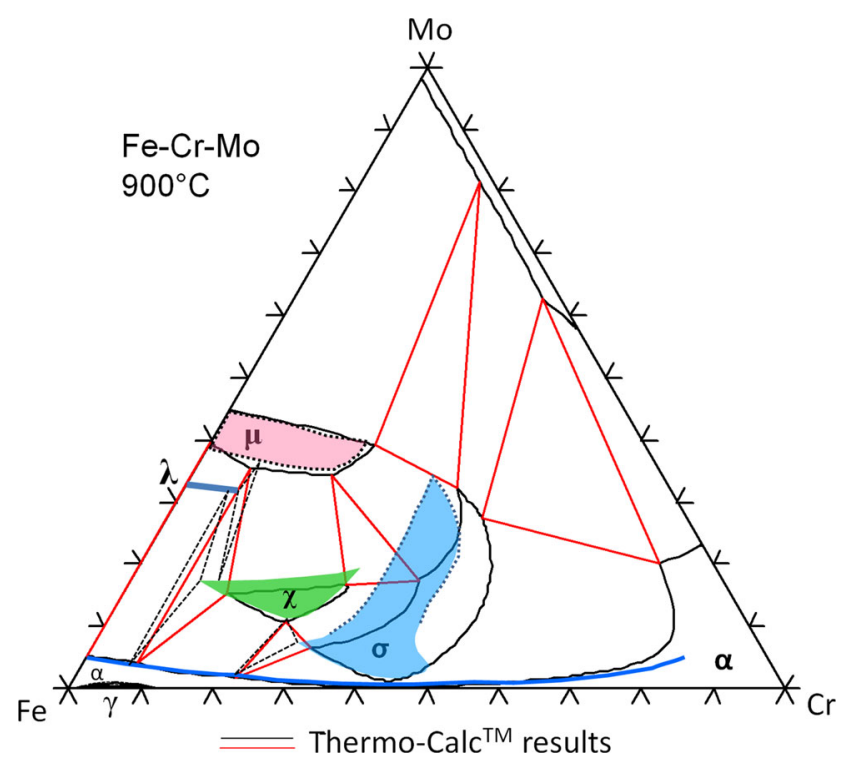

Fig. 8 Comparison of the partial $900{ }^{\circ} \mathrm{C} \mathrm{Fe}-\mathrm{Cr}-\mathrm{Mo}$ results from this study with the computed isothermal section from Thermo$\mathrm{Calc}^{\mathrm{TM}}$ more systematic studies of the phase precipitations and better appreciation of the formation of metastable versus equilibrium phases. To better appreciate this point, one can think of making an alloy of the average composition of area "b", performing an homogenization treatment at $1200{ }^{\circ} \mathrm{C}$, and then performing an $1000-\mathrm{h}$ heat treatment at $800{ }^{\circ} \mathrm{C}$ to try to reach equilibrium. These would be the steps one takes to make samples to determine phase diagrams using the socalled equilibrated alloy method. One would observe the same microstructure as that of Fig. 11(b): needle/thin-platelike R-phase precipitates in the $\alpha$ phase matrix. The conclusion would be that the alloy consisted of two "equilibrium" phases of R and $\alpha$ because one would think 1000 -h heat treatment should have been long enough to reach equilibrium. This conclusion would have been erroneous based on the analysis of DADM Sample \#3.

Figure 11(c), taken from area "c" in Fig. 10, shows $\chi$ phase precipitates on the right. On the left-hand side, the R-phase layer formed during the $1200{ }^{\circ} \mathrm{C}$ annealing has not been decomposed even though $\mathrm{R}$ phase is unstable at $800{ }^{\circ} \mathrm{C}$; again showing the difficulty of decomposing some intermetallics formed at a high-temperature. The DADM approach allows such information to be visible directly, thus helping interpret the equilibrium more systematically.

EPMA was performed to extract tie-line information from large enough precipitates and their adjacent matrix phases. In addition, solubility boundaries are obtained using EPMA point analysis as described before. All the tie-lines and solubility data are summarized in Fig. 12, showing only data that are available for the Fe-rich corner of the isothermal section. Precipitates in other composition regions of the phase diagram are too small to allow reliable composition evaluation using EPMA. TEM and atom probe methods need to be applied to extract the phase equilibrium

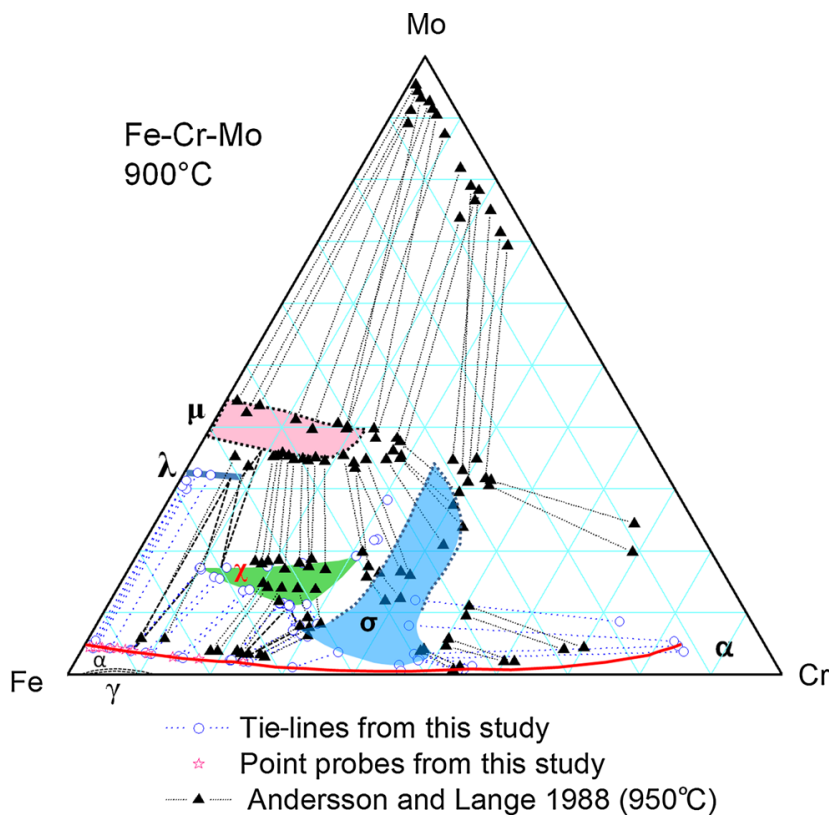

Fig. 9 Comparison of the $900{ }^{\circ} \mathrm{C} \mathrm{Fe}-\mathrm{Cr}-\mathrm{Mo}$ results from this study with experimental data from Andersson and Lange at $950{ }^{\circ} \mathrm{C}$ 


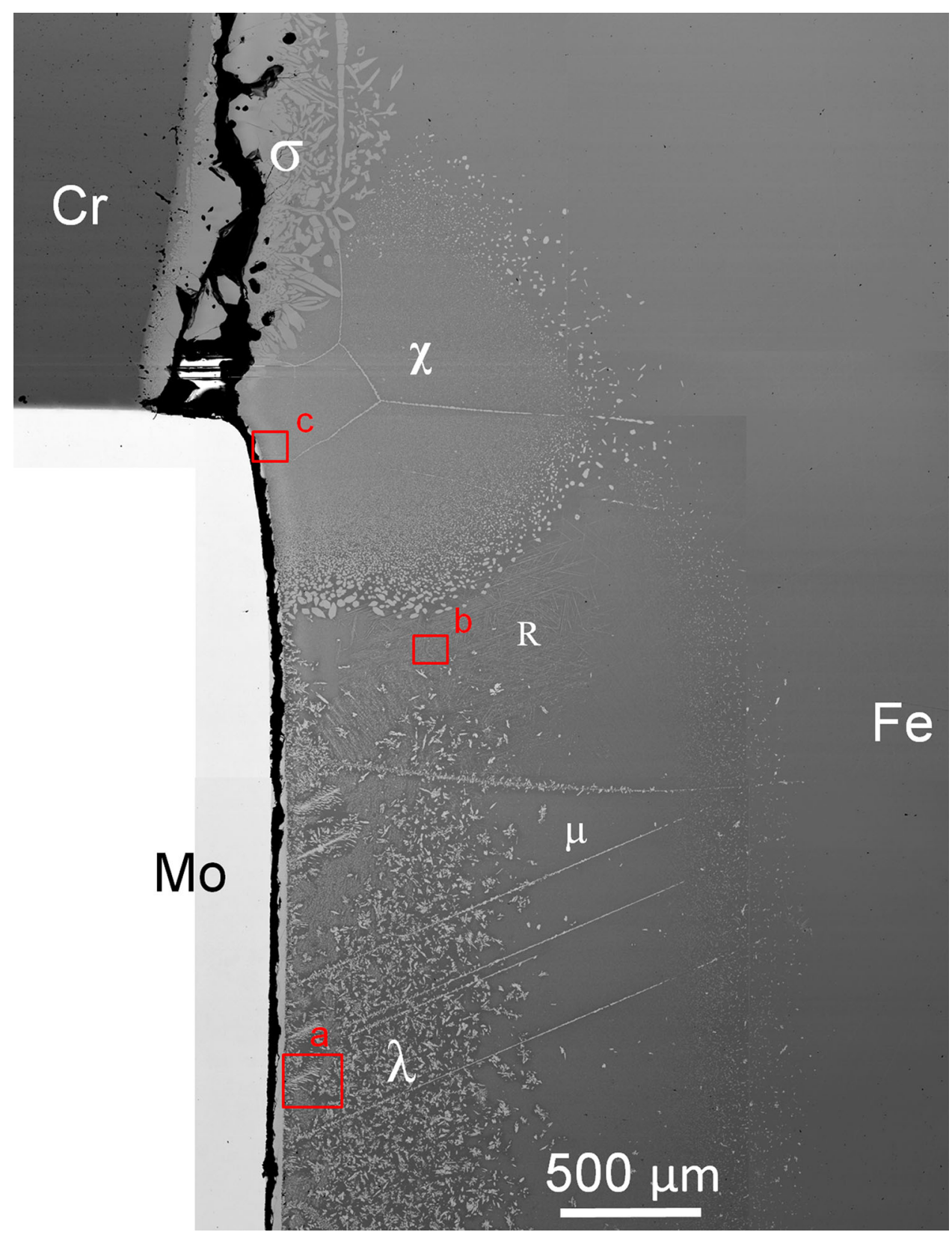

Fig. 10 SEM BSE image montage showing the phase precipitation in the Fe-Cr-Mo tri-junction area of Sample \#3 $\left(1200{ }^{\circ} \mathrm{C}-500 \mathrm{~h}+800{ }^{\circ} \mathrm{C}-1000 \mathrm{~h}\right)$. High magnification images of various regions marked from a to $\mathrm{c}$ are shown in Fig. 11

information from small precipitates. Similar to the $900{ }^{\circ} \mathrm{C}$ results, there is significant solubility of $\mathrm{Cr}$ in the $\lambda$ phase, creating an $\alpha-\lambda-\chi$ three-phase equilibrium (Fig. 13), which is missing from the thermodynamic calculations, Fig. 14. It is necessary to incorporate $\mathrm{Cr}$ into the sublattice model of the $\lambda$ phase in order to correctly compute the $\alpha-\lambda-\chi$ threephase equilibrium in the future. Thermo-Calc ${ }^{\top M}$ with the associated TCFE5 database does a decent job in predicting: (1) the solubility of Mo in the Fe-based $\alpha$ phase, (2) most of the $\alpha / \chi$ equilibrium, and (3) most of the $\alpha / \sigma$ equilibrium. The experimentally determined phase diagram, however, shows that the $\chi$ composition extends as low as $\sim 10$ at. $\% \mathrm{Cr}$ in contrast to the computed result of $\sim 15$ at. $\% \mathrm{Cr}$ and the $\sigma$ phase composition is as low at 30 at.\% $\mathrm{Cr}$ in contrast to the computed result of $\sim 35$ at. $\% \mathrm{Cr}$.

\subsection{The $700^{\circ} \mathrm{C}$ Annealed Sample}

Figures 14 and 15 show the morphologies and precipitates in Sample \#4 that was annealed at $1200{ }^{\circ} \mathrm{C}$ for $500 \mathrm{~h}$ and then $700{ }^{\circ} \mathrm{C}$ for $1000 \mathrm{~h}$. Except for the $\sigma$ phase whose precipitate sizes are large enough for EPMA compositional 

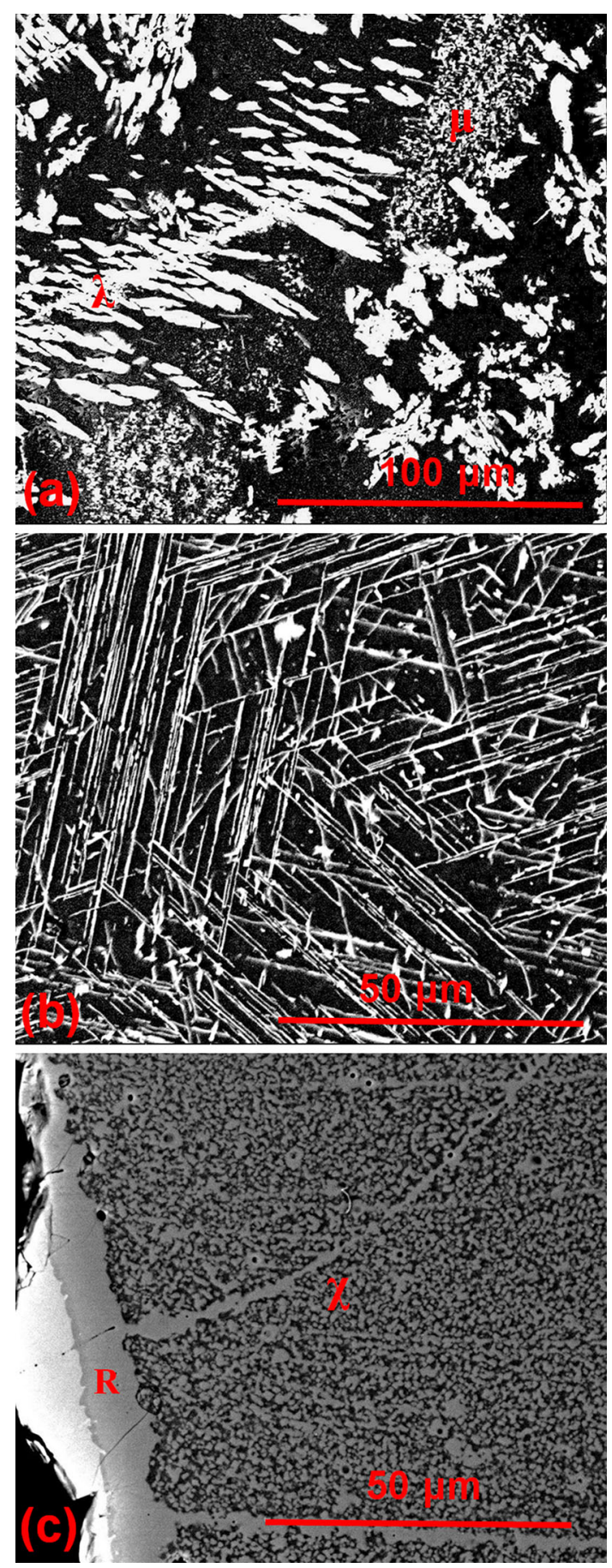

Fig. 11 SEM BSE images showing various precipitates in the Fe-Cr-Mo tri-junction of Sample \#3. The locations of these images are marked in Fig. 10

analysis, all other precipitates are too small to be reliably analyzed using EPMA. This sample vividly illustrates the difficulty in experimentally determining the phase diagrams at intermediate temperatures, especially at the lower-inter-

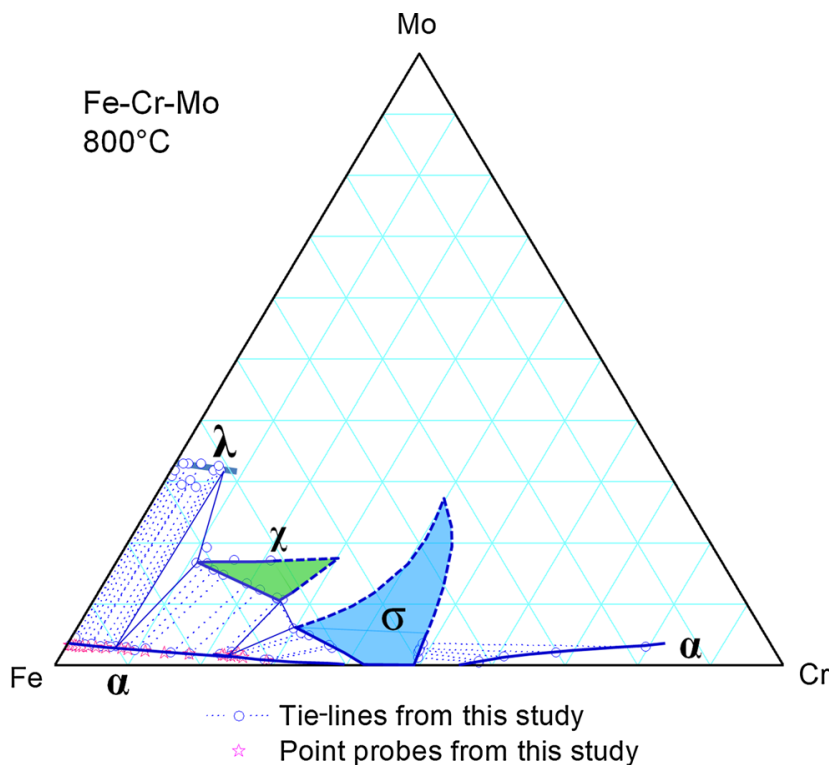

Fig. 12 Fe-rich corner of the partial $800{ }^{\circ} \mathrm{C} \mathrm{Fe}-\mathrm{Cr}-\mathrm{Mo}$ isothermal section determined from this study. The composition is plotted in at.\% axes with the axis numbers removed for simplicity. The dashed phase boundaries are not experimentally determined but just to guide the eyes

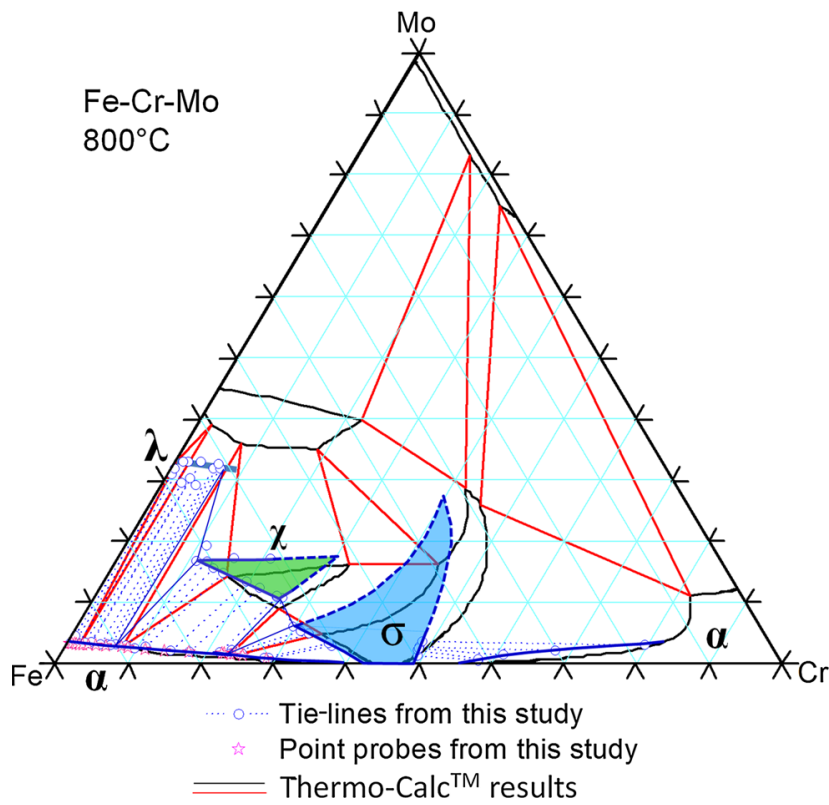

Fig. 13 Comparison of the partial $800{ }^{\circ} \mathrm{C}$ Fe-Cr-Mo results from this study with the computed isothermal section from Thermo-Calc ${ }^{\mathrm{TM}}$

mediate temperatures where we are at the mercy of kinetics. TEM characterization or atom probe analysis will be required in the future to obtain reliable local equilibrium tie-line information to establish the phase diagram as 


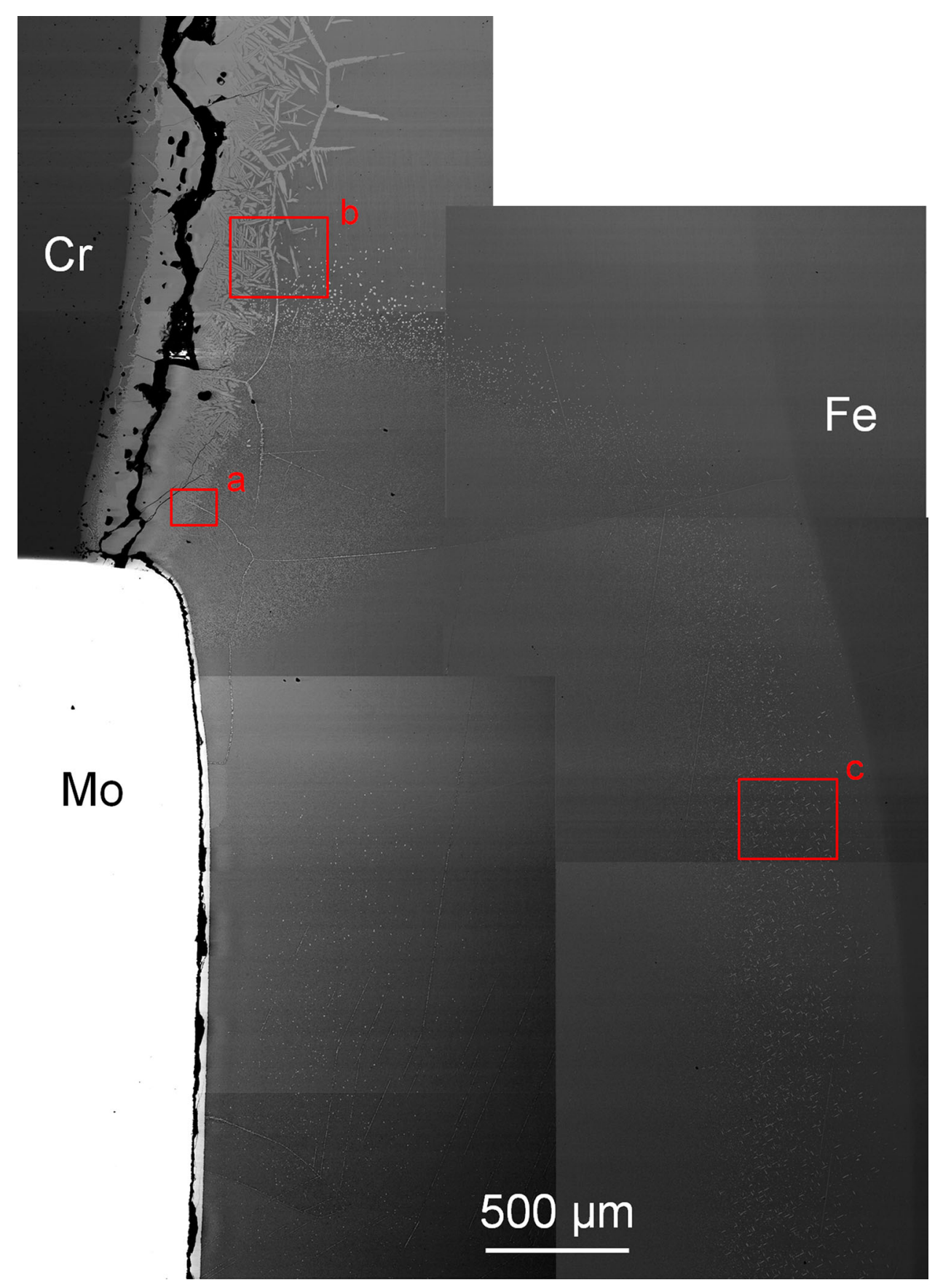

Fig. 14 SEM BSE image montage showing the phase precipitation in the Fe-Cr-Mo tri-junction area of Sample \#4 $\left(1200{ }^{\circ} \mathrm{C}-500 \mathrm{~h}+700{ }^{\circ} \mathrm{C}-1000 \mathrm{~h}\right)$. High magnification images of various regions marked from (a) to (c) are shown in Fig. 15

demonstrated by Romig and Goldstein ${ }^{[18]}$ for the TEM case. The time and effort will be substantial to cut TEM foil samples or atom probe needles from the DADM in order to perform high-resolution EDS compositional analysis or atom probe tomography. Fortunately, localized extraction of TEM foils and atom probe needles using focused ion beam
(FIB) is now a routine practice. Moreover, each DADM sample such as Sample \#4 discussed here offers all the necessary composition variation to allow the establishment of a ternary phase diagram. It would take enormous effort to make many individual alloys, perform thousands of hours of heat treatment on each of them, and then extract TEM or 

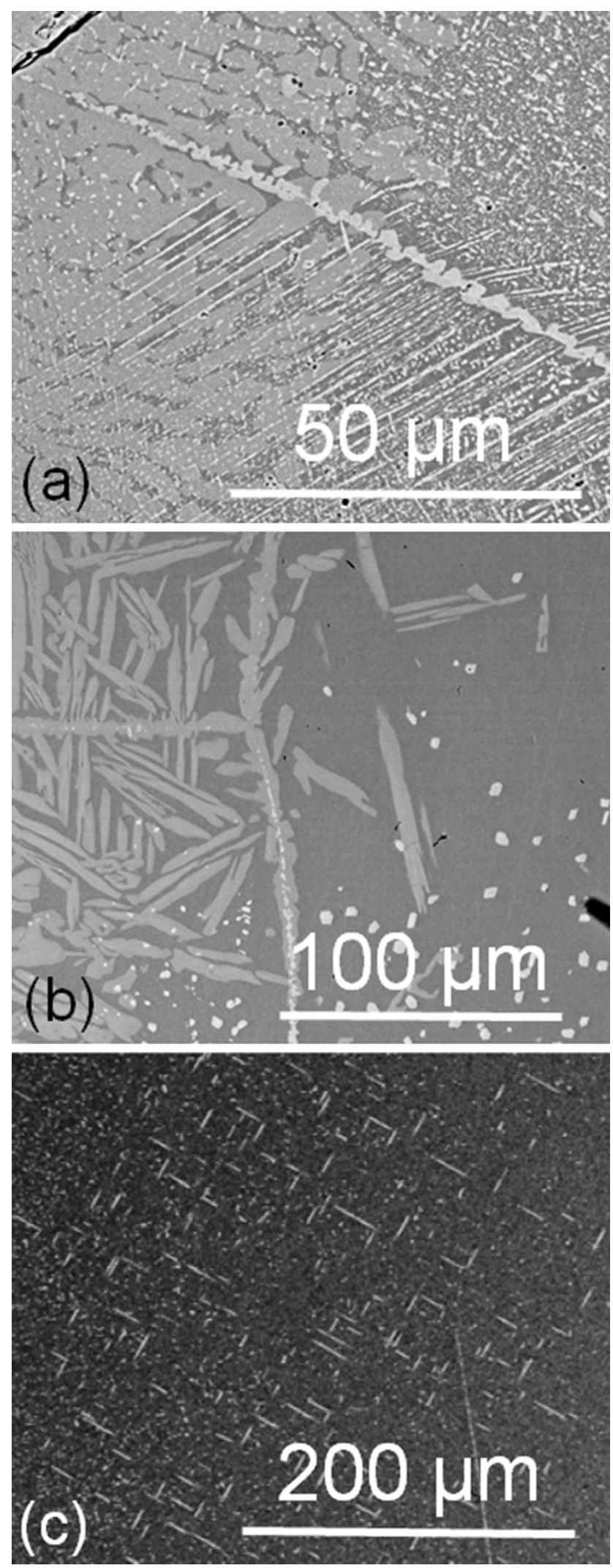

Fig. 15 SEM BSE images showing various precipitates in the Fe-Cr-Mo tri-junction of Sample \#4. The locations of these images are marked in Fig. 14

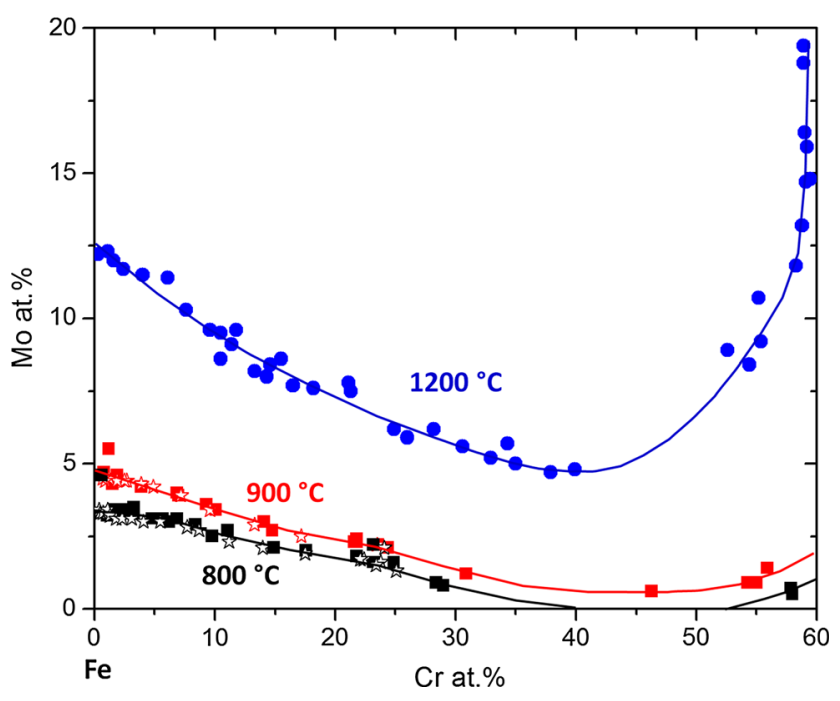

Fig. 16 Mo solubility in the $\alpha$ phase as a function of $\mathrm{Cr}$ concentration obtain from tie-line analysis based on local equilibrium in comparison with the results obtained from EPMA singlepoint measurements tracing the boundary between the precipitate regions and the precipitate-free region. The filled symbols are data from local equilibrium tie-line analysis and the open stars are from EPMA point analysis, showing an excellent agreement

atom probe samples for the compositional analysis of the phases. This is the reason that there is a worldwide shortage of intermediate and low temperature phase diagrams. The DADM approach can help accelerate the determination of such phase diagrams, but would require TEM or atom probe analysis for the lower-intermediate temperature range.

\subsection{Discussion}

The DADMs were able to generate an amazing diversity of microstructures and precipitates in different regions/compositions of the diffusion multiples, which provide systematic information about the precipitation and phase equilibria. At the same time, the small precipitate sizes poise significant challenges to the extraction of phase equilibrium information for the phase diagram establishment. The small precipitate sizes demand careful TEM or atom probe characterization for phase identification as well as local equilibrium tie-line establishment.

The current study was able to establish a reliable $1200{ }^{\circ} \mathrm{C}$ isothermal section for the $\mathrm{Fe}-\mathrm{Cr}$-Mo ternary system. The sluggish kinetics of Mo makes the precipitation much harder. For this reason, the Mo-rich part of the isothermal sections of $\mathrm{Fe}-\mathrm{Cr}-\mathrm{Mo}$ at 900 and $800{ }^{\circ} \mathrm{C}$ were not determined at the present time without TEM characterization. This study have obtained reliable and systematic phase equilibrium data for the Fe-rich corner of the phase diagram for the Fe-Cr-Mo ternary system at both 900 and $800{ }^{\circ} \mathrm{C}$. It is believed that the following data are reliable: (1) the Mo solubility in the Fe-rich and some Cr-rich bec $(\alpha)$ phase; (2) the $\sigma-\alpha$ equilibrium at compositions with less 
than 10 at.\% Mo, and (3) the $\chi-\alpha$ equilibrium. Much more work needs to be performed to extract vast amount of information that exists in the DADMs.

Figure 16 compares the Mo solubility in the $\alpha$ phase (i.e., the $\alpha$ phase boundary) at different temperatures as a function of $\mathrm{Cr}$ concentration obtained from both local-equilibrium tie-line analysis and point probe EPMA measurements tracing the boundary between the precipitate regions and the precipitate-free region (such as the dashed line in Fig. 5). The excellent agreement validates the point-probe method in evaluating the phase boundaries.

\section{Summary}

The Fe-Cr-Mo system is very important for the design of advanced steels. Four sets of $\mathrm{Fe}-\mathrm{Cr}-\mathrm{Ni}-\mathrm{Mo}-\mathrm{Co}$ diffusion multiples were made and heat treated at different temperature and time durations for the determination of phase diagrams of Fe-Cr-Mo at 1200, 900, 800, and $700{ }^{\circ} \mathrm{C}$. Microprobe analysis (EPMA) across the interfaces between large precipitates and the adjacent matrix phases affords the extraction of tie-lines based on local equilibrium at the interfaces. Single point EPMA measurements along the boundary separating the precipitates from the precipitationfree regions provide the solubility data (phase boundaries). It is demonstrated that such solubility data are very reliable since the results agree well with those obtained from equilibrium tie-lines (Fig. 16). Both the tie-lines and solubility data are used to establish isothermal sections of the Fe-Cr-Mo ternary system.

EPMA on the single-anneal diffusion multiple $\left(1200{ }^{\circ} \mathrm{C}-500 \mathrm{~h}\right.$, Sample \#1) provided large amount of phase equilibrium information to construct a reliable $1200{ }^{\circ} \mathrm{C}$ isothermal section for Fe-Cr-Mo system (Fig. 3). The results agree fairly well with available literature results. The $1200{ }^{\circ} \mathrm{C}$ isothermal section provided reliable data for the entire composition range, but the 900 and $800{ }^{\circ} \mathrm{C}$ isothermal sections (Fig. 7 and 12) provided reliable data for only the Fe-rich corner of the Fe-Cr-Mo system. This is due to the sluggish precipitation kinetics at Mo-rich compositions where the melting temperatures are very high. The fine precipitates in Mo-rich compositions in the DADMs made it impractical to perform reliable EPMA composition analysis since the $\mathrm{x}$-ray generation (interaction) volume is larger than the precipitate sizes. It is worth noting that the information for the entire isothermal sections is available in the DADMs, but one needs to resort to TEM and/or atom probe analysis to obtain the missing part of the isothermal sections.

Except for the $\sigma$ phase whose precipitate sizes are large enough for EPMA compositional analysis, all other precipitates in Sample \#4 (1200 ${ }^{\circ} \mathrm{C}$ for $500 \mathrm{~h}$ and $700{ }^{\circ} \mathrm{C}$ for $1000 \mathrm{~h}$ ) are too small to be reliably analyzed using EPMA (Fig. 14 and 15). TEM and/or atom probe analysis will be needed to obtain the isothermal section. This sample vividly illustrates challenges in experimental determination of phase diagrams at intermediate temperatures, especially at the lower-intermediate temperatures where we are at the mercy of kinetics. By comparison, it was possible to use EPMA to obtain the $700{ }^{\circ} \mathrm{C}$ isothermal section of the Fe-Cr-Ni system ${ }^{[1]}$ from the same sample since Ni diffuses much faster than Mo. Even with the lack of reliable data for the $700{ }^{\circ} \mathrm{C}$ isothermal section and Mo-rich compositions at both 900 and $800{ }^{\circ} \mathrm{C}$ (before any TEM and or atom probe analysis), the DADMs have already provided tremendous amount of data for $\mathrm{Fe}-\mathrm{Cr}-\mathrm{Mo}$ at three temperatures, which would otherwise take dozens of individually cast alloys to obtain the same amount of information.

The results of the current study are used to check the results from thermodynamic calculations using ThermoCalc $^{\mathrm{TM}}$ and the TCFE5 database. The thermodynamic parameters for the Fe-Cr-Mo systems need substantial improvements, not only at intermediate temperatures, but also for high temperatures. One can appreciate the difference between the experimental phase diagrams and the computed counterparts in Fig. 4, 8 and 13.

The phase precipitation in the Fe-Cr-Mo system is quite complex. Much more work, especially detailed TEM investigations, need to be performed to fully understand both the intermediate temperature phase stability and the metastability of the phases. FIB local sampling and TEM analysis will be essential.

The amazing diversity of morphologies and phases may prove to be more valuable in the future in studying phase transformation kinetics and precipitation morphology (especially concerning the elastic strain and orientation relationships) than just studying the phase equilibria. The systematic variation of composition in the samples is a rich ground to explore reliable extraction of large amount of information in addition to phase diagrams.

\section{Acknowledgment}

The authors would like to thank Mr. John Donovan and Ms. Julie Chouinard for their help in the microprobe analysis performed at the CAMCOR Facilities of the University of Oregon. This study was performed at The Ohio State University with support from the National Science Foundation (NSF) under grant number DMR-1237577. The diffusion multiple sample components were machined and provided by the Carpenter Technology Corporation.

\section{References}

1. S. Cao and J.-C. Zhao, Application of Dual-Anneal Diffusion Multiples to the Effective Study of Phase Diagrams and Phase Transformations in the Fe-Cr-Ni System, Acta Mater., 2015, 88, p 196-206

2. G.V. Raynor and V.G. Rivlin, Phase Equilibria in Iron Ternary Alloys. XV. Critical Evaluation of Ternary Alloys of Iron and Molybdenum with Cobalt, Chromium, Manganese, and Nickel, Int. Metall. Rev., 1984, 29, p 329-375

3. G.V. Raynor and V.G. Rivlin, $\mathrm{Cr}-\mathrm{Fe}-\mathrm{Mo}$, Phase Equilibria in Iron Ternary Alloys, Institute of Metals, London, 1988, p 300-316

4. V. Raghavan, Cr-Fe-Mo (Chromium-Iron-Molybdenum), J. Phase Equilib., 1994, 15, p 532-533 
5. A. Kroupa, Chromium-Iron-Molybdenum, Ternary Alloy Systems, Landolt-Börnstein, Group IV Physical Chemistry, Vol 11D3, Springer, Berlin, 2008, p 157-183

6. Z. Jin, A Study of the Range of Stability of $\sigma$ Phase in Some Ternary Systems, Scand. J. Metall., 1981, 10, p 279-287

7. J.-O. Andersson and N. Lange, An Experimental Study and a Thermodynamic Evaluation of the Fe-Cr-Mo System, Metall. Trans. A, 1988, 19A, p 1385-1394

8. S. Liu, Y. Hamaguchi, and H. Kuwano, Experimental Determination of the Phase Boundaries of Intermetallic Compounds in the Ternary Fe-Cr-Mo System, Nippon Kinzoku Gakkaishi, 1986, 50, p 1023-1031

9. S. Liu, Y. Hamaguchi, and H. Kuwano, Metastable R-phase in Fe-Cr-Mo and Fe-Cr-W Alloys, Jinshu Xuebao, 1990, 26, p A410-A414

10. S. Liu, Y. Hamaguchi, and H. Kuwano, Intermetallic Compounds and Their Formation Reactions in High Temperature Region of the Fe-Cr-Mo System, Jinshu Xuebao, 1989, 25, p B97-B103

11. S. Liu, H. Kuwano, and Y. Hamaguchi, Precipitation Processes in Fe-Cr-Mo Ternary Alloys, Nippon Kinzoku Gakkaishi, 1988, 52, p 917-926
12. J.-C. Zhao, A Combinatorial Approach for Structural Materials, Adv. Eng. Mater, 2001, 3, p 143-147

13. J.-C. Zhao, Reliability of the Diffusion-Multiple Approach for Phase Diagram Mapping, J. Mater. Sci., 2004, 39, p 39133925

14. J.-C. Zhao, Combinatorial Approaches as Effective Tools in the Study of Phase Diagrams and Composition-StructureProperty Relationships, Prog. Mater Sci., 2006, 51, p 557-631

15. J.-C. Zhao, Phase Diagram Determination Using Diffusion Multiples, Methods for Phase Diagram Determination, J.-C. Zhao, Ed., Elsevier, Amsterdam, 2007, p 246-272

16. J.-C. Zhao, The Role of Phase Transformation Kinetics in Phase Diagram Determination and Assessment, Methods for Phase Diagram Determination, J.-C. Zhao, Ed., Elsevier, Amsterdam, 2007, p 22-50

17. M. Hillert and C. Qiu, A Reassessment of the Fe-Cr-Mo-C System, J. Phase Equilib., 1992, 13, p 512-521

18. A.D. Romig, Jr, and J.I. Goldstein, Determination of the Fe-Ni and Fe-Ni-P phase Diagrams at Low Temperatures (700 to $300{ }^{\circ} \mathrm{C}$ ), Metall. Trans., 1980, 11A, p 1151-1159 